\title{
Hepatitis A Vaccination Rates and Related Factors in a 2005 Population-based Study in Nonsan, Korea
}

\author{
Eun Young $\mathrm{Kim}^{1}$, Baeg Ju Na${ }^{1}$, Moo Sik Lee ${ }^{1}$, Keon Yeop Kim² ${ }^{2}$ Moran $\mathrm{Ki}^{3}$ \\ 'Department of Preventive Medicine, School of Medicine, Konyang University, Daejeon; 'Department of Preventive Medicine, School of \\ Medicine, Kyungpook National University, Daegu; ${ }^{3}$ Department of Preventive Medicine, Eulji University School of Medicine, Daejeon, Korea
}

\begin{abstract}
OBJECTIVES: The incidence of clinical hepatitis A has increased in young Korean adults since the mid-1990s. Although hepatitis A vaccinations have been administered in private clinics over the past $10 \mathrm{yr}$, no data exist on the vaccination rate and relating factors.

METHODS: In 2005, a population-based survey of 12-35-month-old children was carried out in Nonsan, Korea. An interview survey was completed for $71.3 \%$ of the children. All data came from a vaccination card or confirmation from a provider.

RESULTS: The hepatitis A vaccination rate was $42.3 \%$ for $\geq 1$ dose and $24.7 \%$ for 2-dose. The results of the multivariate regression analysis for the hepatitis A vaccination showed that the second $(\mathrm{OR}=1.6)$ and third and successive children $(\mathrm{OR}=3.3)$ were less often immunized than the first child. Low economic status $(\mathrm{OR}=$ 1.6), rural area $(\mathrm{OR}=1.5)$ and employed mother $(\mathrm{OR}=1.5)$ were also correlated with a lower vaccination rate. The hepatitis A vaccination rate was significantly lower in children who had no other vaccinations: measlesmumps-rubella ( $\mathrm{OR}=2.8$ for $\geq 1$ dose and 7.3 for 2-dose), varicella ( $\mathrm{OR}=20.2$ and 22.0, respectively) and $\mathrm{Ha}$ emophilus influenza type b (OR=14.3 and 13.3, respectively).

CONCLUSION: To prevent outbreaks of clinical hepatitis A by enough herd immunity, a vaccination should be included in the National Immunization Program and a vaccination policy developed and implemented that can overcome the barriers to immunization such as late birth order and a mother's employment (Epidemiol Health 2009;31:e2009003).
\end{abstract}

KEY WORDS: Hepatitis A, Immunization, Infant, Risk factors, Vaccination

\section{Correspondence to :}

\section{Moran Ki}

Department of Preventive Medicine, Eulji University School of Medicine, 143-5 Yongdu-dong, Jung-gu, Daejeon 301-746, Korea

Tel : +82-42-259-1681 Fax : +82-42-259-1689

E-mail : kimoran@eulji.ac.kr

*Presented in part at the 57th Korean Society for Preventive Medicine Fall Meetings, Korea 25-26 October 2005.

Received: Jun 4, 2009, Accepted: Sep 24, 2009, Published: Oct 12, 2009 This article is available from: http://e-epih.org/.

(C) 2009, Korean Society of Epidemiology

(c) This is an open-access article distributed under the terms of the Creative Commons Attribution License, which permits unrestricted use, distribution, and reproduction in any medium, provided the original work is properly cited.

\section{INTRODUCTION}

Hepatitis A is generally an acute, self-limiting infection of the liver by an enterically transmitted picornavirus, the hepatitis A virus (HAV) [1]. Hepatitis A occurs worldwide, but its prevalence is closely related to hygiene, sanitary conditions and other indicators of a developed country. Although the effective method for controlling enteric infections including hepatitis A is to improve standards of hygiene and sanitation [2], HAV vaccinations have been included in the National Immunization Programs (NIPs) of several developed countries to reduce the number of severe clinical cases in young adults by enough herd immunity [3]. In Korea, hepatitis A did not seem to be a serious disease before 1990 because of the natural immunity derived from hepatitis A infection. Since the mid-1990s, however, the incidence of clinical hepatitis A in 
young adults has increased. In 2008, 7,895 cases of hepatitis A were detected by sentinel surveillance, which is 3.5 times higher than the number of cases reported in 2007. According to health insurance data, the incidence of HAV was 65.3 cases per 100,000 in 2008, which is 2.3 times higher than the 28.7 cases per 100,000 reported in 2007 (author's study, unpublished data).

Several papers reported this epidemiological shift in the HAV and called for a hepatitis A vaccination in Korea [4, 5]. Since 1997, four inactivated hepatitis A vaccines have been licensed in Korea; Havrix (GlaxoSmithKline Biologicals, Rixensart, Belgium) and VAQTA (Merck \& Co., Inc., PA, USA) have been approved for use in the United States, and AVAXIM (Sanofi Pasteur, Lyon, France) and Epaxal (Berna Biotech Ltd., Bern, Switzerland) are licensed in Europe, Canada and several other countries [6]. Havrix and VAQTA are the most used in Korea, but VAQTA has not been used since 2008. In the United States, hepatitis A vaccines were administered to high-risk children in 1996, and in 1999 were included in routine immunization programs in 11 states. They were included in the NIP in 2006 [7]. In Korea, the hepatitis A vaccination is not part of the NIP, and no data exist on the vaccination coverage and the factors related to having a child vaccinated. We report the hepatitis A vaccination rate based on a population-based survey of 12-35-month-old children conducted in 2005 in an area with both urban and rural populations. We also present barriers for hepatitis A immunization and discuss the implications for identifying barriers associated with immunization.

\section{MATERIALS AND METHODS}

\section{Study population}

The population-based survey was carried out between February and April 2005 in Nonsan city. Nonsan has both urban and rural populations, and has a low rate of migration. The target population was 2,188 12-35-month-old children living in Nonsan. The interview survey was completed for 1,561 children $(71.3 \%)$ and of those 68 did not keep vaccination records; therefore, 1,493 children were included in the analysis. Interviewers were students from medical school or school of public health, who were trained on the study objectives and interviewing methods. We sent a letter to the study subjects before the survey and visited their house. When we could not meet the subjects after three visits, we ascertained the subjects' whereabouts by neighbours or representatives of the town. Many of them did not reside in the town or were living in facilities for orphans or the poor. The primary caregivers of all the children were interviewed and gave written informed consent.

\section{Vaccination history and analysis}

When a vaccination card was available, the interviewer transcribed all immunization doses and dates to a standardized recording form. A report from recall was not accepted without a vaccination card or confirmation from a health provider. During analysis, vaccination rates were split by age group (1223 months and 24-35 months) and odds ratios (ORs) were adjusted because the vaccination rate can be increased by age. For the economic status, we asked the subjective question "which category is appropriate for your economic status?". When the answers were 'very rich' or 'rich' they were classified as 'high' economic status, 'ordinary' as 'medium' and 'poor' or 'very poor' as 'low'.

For health security, we checked the health insurance or medical aid card and the numbers for confirmation.

Chi-square tests were used to compare rates, and a multiple logistic regression model included all variables that were statistically significant in a univariate analysis except confounding variables. All analyses were conducted using SPSS Ver. 14.0 (SPSS Inc., Chicago, USA).

\section{RESULTS}

The hepatitis A immunization rate for children aged 12-35 months was $42.3 \%$ for $\geq 1$ dose and $24.7 \%$ for 2 -dose. Among children 24-35 months of age, the rates for $\geq 1$ dose and 2dose were $45 \%$ and $35.2 \%$, respectively. The immunization rate was significantly lower in rural areas $(47.1 \%$ for urban areas and $36.7 \%$ for rural areas for $\geq 1$ dose), late birth order (53.0\% for the first child, $39.2 \%$ for the second child and 24.2 $\%$ for the third and successive children for $\geq 1$ dose, and 33.0 $\%, 21.9 \%$ and $11.7 \%$ for 2 -dose, respectively), large number of siblings (50.5\% for no siblings, $44.0 \%$ for one sibling and $26.6 \%$ for two or more siblings for $\geq 1$ dose, and $28.7 \%, 27.0$ $\%$ and $12.9 \%$ for 2 -dose, respectively) and when the primary caregiver was not the parent $(43.6 \%$ for parent and $35.2 \%$ for others for $\geq 1$ dose, and $25.9 \%$ and $18.8 \%$ for 2 -dose, respectively). No significant difference in the immunization rate was found for gender (Table 1).

The hepatitis A immunization rate was significantly lower in children whose parents had a low economic status for $\geq 1$ dose $(p<0.001)$ and 2-dose $(p=0.004)$. Mothers who were employed and those who unmarried were significantly less likely to have their children vaccinated for $\geq 1$ dose $(p=0.002$ and $\mathrm{p}=0.034$, respectively; Table 2 ). The parents' level of health security was borderline significant, and the mother's level of education did not significantly influence whether a child was vaccinated.

The hepatitis A immunization rate was significantly lower 
in children who had not received other childhood vaccinations. Children who were not immunized against measles-mumpsrubella (MMR) received HAV vaccination 2.8 times less often for $\geq 1$ dose and 7.3 times less often for 2-dose. MMR vaccinees immunized at a public health center were less likely to be immunized against hepatitis A than children immunized at a private clinic $(29.8 \%$ for a public health centre and $71.0 \%$ for a private clinic for $\geq 1$ dose of hepatitis $\mathrm{A}$, and $15.7 \%$ and $47.4 \%$ for 2-dose, respectively (data not shown).

Children who were not immunized against varicella were also not immunized against the HAV 20.2 times more for $\geq$ 1 dose and 22.0 times more for 2-dose. In comparison with the children who had received the Haemophilus influenza type $b$ (Hib) vaccination of $\geq 1$ dose, the children who had received no Hib vaccination were at risk of no immunization against hepatitis $\mathrm{A}(\mathrm{OR}=14.3$ for $\geq 1$ dose and $\mathrm{OR}=13.3$ for 2-dose Table 3).

The result of the age-adjusted logistic regression model was

Table 1. Vaccination rate of hepatitis A by general characteristics of children in Nonsan, 2005

\begin{tabular}{|c|c|c|c|c|}
\hline \multirow[b]{2}{*}{ Characteristics (n) } & \multicolumn{2}{|c|}{$\geq 1$ dose } & \multicolumn{2}{|c|}{ 2-dose } \\
\hline & $\begin{array}{c}\text { Vaccination } \\
\text { rate (\%) }\end{array}$ & $p$ value $^{*}$ & $\begin{array}{c}\text { Vaccination } \\
\text { rate (\%) }\end{array}$ & p value* \\
\hline \multicolumn{5}{|l|}{ Gender } \\
\hline Male (777) & 41.3 & & 24.3 & \\
\hline Female (716) & 43.3 & 0.438 & 25.1 & 0.715 \\
\hline \multicolumn{5}{|l|}{ Child's age (month) } \\
\hline $12-23(724)$ & 39.4 & & 13.5 & \\
\hline $24-35(769)$ & 45.0 & 0.028 & 35.2 & $<0.001$ \\
\hline \multicolumn{5}{|l|}{ Geographical area } \\
\hline Urban (803) & 47.1 & & 26.4 & \\
\hline Rural (690) & 36.7 & $<0.001$ & 22.8 & 0.103 \\
\hline \multicolumn{5}{|l|}{ Birth order } \\
\hline First (606) & 53.0 & & 33.0 & \\
\hline Second (636) & 39.2 & & 21.9 & \\
\hline Third+ (248) & 24.2 & $<0.001$ & 11.7 & $<0.001$ \\
\hline Missing (3) & - & & - & \\
\hline \multicolumn{5}{|l|}{ No. of sibling } \\
\hline $0(418)$ & 50.5 & & 28.7 & \\
\hline $1(777)$ & 44.0 & & 27.0 & \\
\hline $2+(286)$ & 26.6 & $<0.001$ & 12.9 & $<0.001$ \\
\hline Missing (12) & - & & - & \\
\hline \multicolumn{5}{|l|}{ Primary caregiver } \\
\hline Parent $(1,233)$ & 43.6 & & 25.9 & \\
\hline Other (256) & 35.2 & 0.012 & 18.8 & 0.016 \\
\hline Missing (4) & - & & - & \\
\hline Total $(1,493)$ & 42.3 & & 24.7 & \\
\hline
\end{tabular}

${ }^{*} \mathrm{p}$ value obtained by $\chi^{2}$ test similar to the multivariate model; the multivariate model included age, birth order, economic status, geographical area and mother's employment status. The analysis revealed that the second child $(\mathrm{OR}=1.6)$ and the third or successive child

Table 2. Vaccination rate of hepatitis A by general characteristics of subject's parents in Nonsan, 2005

\begin{tabular}{|c|c|c|c|c|}
\hline \multirow[b]{2}{*}{ Characteristics (n) } & \multicolumn{2}{|c|}{$\geq 1$ dose } & \multicolumn{2}{|c|}{ 2-dose } \\
\hline & $\begin{array}{c}\text { Vaccination } \\
\text { rate (\%) }\end{array}$ & p value* & $\begin{array}{l}\text { Vaccination } \\
\text { rate (\%) }\end{array}$ & $p$ value* \\
\hline \multicolumn{5}{|l|}{ Economic status } \\
\hline Low (207) & 29.5 & & 16.9 & \\
\hline Medium+ $(1,267)$ & 44.4 & $<0.001$ & 26.1 & 0.004 \\
\hline Missing (19) & - & & - & \\
\hline \multicolumn{5}{|l|}{ Mother's employment } \\
\hline No (1059) & 45.0 & & 26.3 & \\
\hline Yes (357) & 35.6 & 0.002 & 22.7 & 0.181 \\
\hline Missing (77) & - & & - & \\
\hline \multicolumn{5}{|l|}{ Marital status } \\
\hline Married $(1,431)$ & 42.6 & & 24.7 & \\
\hline Others (36) & 25.0 & 0.034 & 16.7 & 0.226 \\
\hline Missing (26) & - & & - & \\
\hline \multicolumn{5}{|l|}{ Health security } \\
\hline $\begin{array}{l}\text { Health insurance } \\
(1,435)\end{array}$ & 42.8 & & 25.1 & \\
\hline Medical aid (50) & 30.0 & 0.072 & 16.0 & 0.143 \\
\hline Missing (8) & - & & - & \\
\hline \multicolumn{5}{|l|}{ Mother's education } \\
\hline$\leq$ High school (928) & 40.9 & & 25.1 & \\
\hline$\geq$ College (541) & 45.1 & 0.120 & 24.8 & 0.885 \\
\hline Missing (24) & - & & - & \\
\hline Total $(1,493)$ & 42.3 & & 24.7 & \\
\hline
\end{tabular}

${ }^{*} p$ value obtained by $\chi^{2}$ test

Table 3. Vaccination rate and risk for non-vaccination of hepatitis $A$ by other vaccinations in Nonsan, 2005

\begin{tabular}{|c|c|c|c|c|}
\hline \multirow[t]{2}{*}{ Vaccine (n) } & \multicolumn{2}{|c|}{$\begin{array}{l}\text { Vaccination rate } \\
\text { of hepatitis } A(\%)\end{array}$} & \multicolumn{2}{|c|}{$\begin{array}{l}\text { Age-adjusted } \\
\text { OR }(95 \% \mathrm{Cl})\end{array}$} \\
\hline & $\geq 1$ dose & 2-dose & $\geq 1$ dose & 2-dose \\
\hline \multicolumn{5}{|l|}{ MMR } \\
\hline Yes $(1,362)^{*}$ & 44.3 & 26.7 & 1.0 & 1.0 \\
\hline No (131) & 21.4 & 3.8 & $2.8(1.8-4.3)$ & $7.3(3.0-18.2)$ \\
\hline \multicolumn{5}{|l|}{ Varicella } \\
\hline Yes $(1,108)^{*}$ & 55.0 & 32.5 & 1.0 & 1.0 \\
\hline No (385) & 5.7 & 2.3 & $20.2(12.9-31.5)$ & $22.0(11.2-43.3)$ \\
\hline \multicolumn{5}{|c|}{ Haemophilus influenza type b } \\
\hline Yes $(793)^{*}$ & 68.1 & 41.5 & 1.0 & 1.0 \\
\hline No $(700)$ & 13.0 & 5.7 & $14.3(11.0-18.7)$ & $13.3(9.3-19.1)$ \\
\hline
\end{tabular}

OR, odds ratio; $\mathrm{Cl}$, confidence interval.

${ }^{*}$ Children who have vaccination one dose or more. 
Table 4. Risk factors for non-vaccination of hepatitis A in Nonsan, 2005

\begin{tabular}{|c|c|c|c|c|}
\hline \multirow{2}{*}{ Variables (reference) } & \multicolumn{2}{|c|}{ Age adjusted OR (95\% Cl) } & \multicolumn{2}{|c|}{ Multivariate adjusted ${ }^{\star} \mathrm{OR}(95 \% \mathrm{Cl})$} \\
\hline & $\geq 1$ dose & 2-dose & $\geq 1$ dose & 2-dose \\
\hline \multicolumn{5}{|l|}{ Birth order (first) } \\
\hline Second & $1.7(1.4-2.2)$ & $1.8(1.4-2.3)$ & $1.6(1.3-2.1)$ & $1.8(1.3-2.3)$ \\
\hline Third+ & $3.5(2.5-4.9)$ & $3.9(2.5-6.0)$ & $3.3(2.3-4.6)$ & $3.7(2.4-5.8)$ \\
\hline \multicolumn{5}{|c|}{ Economic status (medium+) } \\
\hline Low & $1.9(1.4-2.6)$ & $1.7(1.2-2.6)$ & $1.6(1.2-2.3)$ & $1.6(1.0-2.4)$ \\
\hline \multicolumn{5}{|c|}{ Geographical area (urban) } \\
\hline Rural & $1.5(1.3-1.9)$ & $1.3(1.0-1.6)$ & $1.5(1.2-1.8)$ & $1.3(0.9-1.7)$ \\
\hline \multicolumn{5}{|c|}{ Mother's employment (no) } \\
\hline Yes & $1.5(1.2-1.9)$ & $1.3(1.0-1.7)$ & $1.5(1.2-2.0)$ & $1.2(0.9-1.5)$ \\
\hline
\end{tabular}

OR, odds ratio; $\mathrm{Cl}$, confidence interval.

*Logistic regression model included age, birth order, economic status, geographical area and mother's employment.

$(\mathrm{OR}=3.3)$ were less often immunized than the first child for $\geq 1$ dose of hepatitis A. Low economic status ( $\mathrm{OR}=1.6)$, rural residence $(\mathrm{OR}=1.5)$ and an employed mother $(\mathrm{OR}=1.5)$ were significantly decreased for $\geq 1$ dose of the hepatitis A vaccination. The ORs for birth order and economic status for 2dose were similar to those for $\geq 1$ dose; however, geographical area and mother's employment status were not significant for 2-dose (Table 4).

\section{DISCUSSION}

The immunization rate for hepatitis A among 12-35-monthold Korean children was low: $42.3 \%$ for $\geq 1$ dose and $24.7 \%$ for 2-dose. Our data indicate that the immunization rate for hepatitis A is significantly lower than that for vaccines part of the NIP, such as MMR (91.2\%) and varicella (74.2\%, the vaccine was included in the NIP in 2005) [8]. Hib is excluded from the NIP, but the immunization rate for one or more dose was $53.1 \%$, higher than that for hepatitis A.

The hepatitis A vaccine coverage (two doses) in Korea has been estimated to be $41.6 \%$ based on the amount of hepatitis A vaccine sold between 1998 and 2006 [9]. However, this study did not account for vaccine doses that were unused and immunization in other age groups, and the figure could be an overestimate.

In 2006, the seroprevalence of the HAV was reported to be $55.6 \%$ in children aged $1-4 \mathrm{yr}$ and $47.2 \%$ in those aged 5-9 yr [10]. In general, $90-100 \%$ of children one year of age and older and adults had protective concentrations of the antibody four weeks after one dose of the vaccination [6]. AntiHAV has been shown to persist for at least 10-12 yr after vaccination in 5-6-yr-old children $[11,12]$. The seropositive rate of hepatitis A was 10.1\% (34/337) for 10-24-yr-olds born between 1984 and 1996, i.e., before the hepatitis A vaccine was introduced in Korea, 27.1\% for people aged 25-29 yr, $73.2 \%$ for $30-39$-yr-olds and $96 \%$ for $40-49-y r-o l d s$ [10]. This means that since the mid-1980s the natural infection rate of hepatitis A has been less than $10 \%$ in Korea. Therefore, most Korean children aged 1-9 yr who are immune to hepatitis A received immunity from a vaccination, and natural immunity through a hepatitis A infection is likely to be less than $10 \%$.

In the United States in 2003, vaccination coverage of $\geq 1$ dose was $50.9 \%$ for children living in the 11 states in which routine hepatitis A vaccination is recommended, $25 \%$ for those living in the six states in which hepatitis A vaccination is considered and $1.4 \%$ for the 33 states without a specific recommendation [13]. Israel was the first country worldwide to implement a universal HAV immunization program in which toddlers born after 1997 received two doses of the HAV vaccine at 18 and 24 months [14]. Overall vaccine coverage in the first years after implementation of the program (2001-2002) was $\sim 90 \%$ for $\geq 1$ dose and $\sim 85 \%$ for 2 -dose [14]. In the birth cohort of 2000 in southern Israel, HAV vaccine coverage was $85.5 \%$ for $\geq 1$ dose and $74.9 \%$ for 2 -dose by age three [15]. If the hepatitis A vaccination was recommended as a routine immunization in Korea and free vaccinations were offered at a public health center, vaccination coverage would increase to the level of the NIP vaccines.

In this study, birth order was the factor most highly correlated with hepatitis A vaccination rate. The first child had the highest rate of vaccination followed by the second and then the third and successive children. This finding agrees with other studies on birth order and immunization rates [16, 17]. Birth order might be a proxy parameter of a parent's concern for the child. In this study, economic status was also related to 
Table 5. Calculation of relative prevalence after stratifying by mother's employment; observed association of primary caregiver and vaccination of hepatitis A was a result of confounding by a mother's employment

\begin{tabular}{|c|c|c|c|c|}
\hline & & \multicolumn{2}{|c|}{ Vaccination of hepatitis A (\%) } & \\
\hline & & Yes & No & \\
\hline Mother's employment & Primary caregiver & & & Relative prevalence $(95 \% \mathrm{Cl})$ \\
\hline \multirow[t]{3}{*}{ Yes } & Parent & $62(36.0)$ & $110(64.0)$ & $36.0 \% / 34.6 \%=1.0(0.8-1.4)$ \\
\hline & Other & $63(34.6)$ & $119(65.4)$ & \\
\hline & Total & $125(35.3)$ & $229(64.7)$ & \\
\hline \multirow[t]{3}{*}{ No } & Parent & $460(45.3)$ & $556(54.7)$ & $45.3 \% / 38.1 \%=1.2(0.8-1.8)$ \\
\hline & Other & $16(38.1)$ & $26(61.9)$ & \\
\hline & Total & $476(45.0)$ & $582(55.0)$ & \\
\hline
\end{tabular}

$\mathrm{Cl}$, confidence interval.

vaccination rate. A hepatitis $\mathrm{A}$ vaccination administered in a private clinic is expensive (about $\$ 40$ for a single dose), and cost is a well-known barrier to immunization [18]. Geographical area was also significantly related to immunization rate: the rate was lower in rural than in urban areas. Because hepatitis $\mathrm{A}$ is excluded from the NIP, it is only offered in private clinics, which are more common in urban areas. Furthermore, private clinics are less accessible in rural areas, where the transportation system is less convenient. The barriers for immunization of hepatitis A can be different to other vaccinations in the NIP. In this survey, the significant risk factors for immunization of the NIP were birth order, primary caregiver, mother's employment and marital status; economic status and geographical area were not related to the immunization of the NIP [8]. In the United States, the coverage rate of hepatitis A was higher among children living in urban areas whatever vaccination policy (recommended, considered and not recommended) [13], and in metropolitan areas [19].

Children of employed mothers had a lower vaccination rate, perhaps because those mothers had less time to go to clinics to obtain information about the HAV or to have their children immunized against it. The univariate analysis indicated that the immunization rate was lower when the primary caregiver was not a parent. However, when it was stratified by the mother's employment status, the primary caregiver was no longer significant and mother's employment status was found to be a confounding factor (Table 5). Therefore, the primary caregiver factor was excluded from the multivariate analysis.

The risk factors associated with low immunization coverage can be divided into two groups: parental factors such as poverty, low education and lack of parental care, and provider factors such as health care facility, public health system provision of free vaccines and vaccination policy [18].

This is the first report on the factors associated with the hep- atitis A immunization rate in Korea. Our data, however, are derived from one area and thereby are not representative of the entire country. The vaccination histories were based on information taken from vaccination cards. Children without a vaccination record were excluded and many of them were institutionalized; therefore, we might have overestimated the immunization rate.

The WHO suggests that hepatitis A immunization is a cost effective public health tool to control the disease in countries where clinical hepatitis A is a major health problem [20]. The incidence of clinical hepatitis A has recently increased sharply in Korea, and we recommend that the hepatitis A vaccination be included in the NIP. To control the high incidence of hepatitis A in 20-39 yr-olds in Korea, catch-up immunization might also be considered.

In this study, late birth order (less parental concern), low economic status (high cost of vaccination), rural area (low accessibility to a private clinic) and the mother's employment (mother's time commitments) decreased the hepatitis A vaccination rate. The cost and accessibility factors could be alleviated if the hepatitis A vaccination was included in the NIP. However, parental concern and mother's time commitments will continue to affect the hepatitis A immunization rate. Therefore, a vaccination policy that can overcome these barriers should be developed and implemented to increase the immunization rate.

\section{CONFLICTS OF INTEREST}

No author has a commercial or other association that might pose a conflict of interest. 


\section{ACKNOWLEDGMENTS}

This work was supported by the Korea Research Foundation Grant funded by the Korean government (MOEHRD, Basic Research Promotion Fund, KRF-2007-E00008) and a Korea Centers for Disease Control and Prevention grant (Development of vaccination coverage estimation methods and evaluation indicators of the NIP in Korea, 2005).

\section{REFERENCES}

1. Catton MG, Locarnini SA. Epidemiology. In: Thomas HC, Lemon SM, Zuckerman AJ, editors. Viral Hepatitis. 3rd ed. Massachusetts: Blackwell; 2005. p. 92-108.

2. Bell BP, Anderson DA, Feinstone SM. Hepatitis A virus. In: Mandell GL, Douglas RG, Bennett JE, Dolin R, editors. Mandell, Douglas, and Bennett's principles and practice of infectious diseases. 6th ed. Philadelphia: Elsevier Churchill Livingstone; c2005.

3. Hendrickx G, Van Herck K, Vorsters A, Wiersma S, Shapiro C, Andrus JK, et al. Has the time come to control hepatitis A globally? Matching prevention to the changing epidemiology. J Viral Hepat 2008;15:1-15.

4. Jeong SH. Current status and vaccine indication for hepatitis A virus infection in Korea. Korean J Gastroenterol 2008;51:331-337. (Korean)

5. Lee D, Cho YA, Park Y, Hwang JH, Kim JW, Kim NY, et al. Hepatitis A in Korea: epidemiological shift and call for vaccine strategy. Intervirology 2008;51:70-74.

6. Fiore A, Feinstone SM, Bell BP. Hepatitis A vaccines. In: Plotkin SA, Orenstein WA, Offit PA, editors. Vaccines. 5th ed. Philadelphia: Saunders Elsevier; 2008. p.177-203.

7. Lieberman JM, Word BM, Jacobs RJ, Dagan R, Marchant CD. Universal hepatitis A vaccination in the United States-A call for action. Pediatr Infect Dis J 2008;27:287-291.

8. Lee M, Kwon S, Ki M, Kim K, Na B, Nam H, et al. Development of Vaccination Coverage Estimation Methods and Evaluation Indicators of National Immunization Program in Korea. Seoul: Korea
Center for Disease Control, 2005.

9. Kim JH. Recent epidemiological status and vaccination of hepatitis A in Korea. J Korean Med Assoc 2008;51: 110-118. (Korean)

10. Kim JH, Kang J, Lee S, Choi H, Kim H, Seo K, et al. A study for seroprevalence of antibody to hepatitis A in Korea. Korean J Hepatol 2007;13:s27. (Korean)

11. Van Damme P, Banatvala J, Fay O, Iwarson S, McMahon B, Van Herck $\mathrm{K}$, et al. Hepatitis A booster vaccination: is there a need? Lancet 2003;362:1065-1071.

12. Hammitt LL, Bulkow L, Hennessy TW, Zanis C, Snowball M, Williams JL, et al. Persistence of antibody to hepatitis A virus 10 years after vaccination among children and adults. J Infect Dis 2008;198: 1776-1782.

13. Amon JJ, Darling N, Fiore AE, Bell BP, Barker LE. Factors associated with hepatitis A vaccination among children 24 to 35 months of age: United States, 2003. Pediatrics 2006;117:30-33.

14. Dagan R, Leventhal A, Anis E, Slater P, Ashur Y, Shouval D. Incidence of hepatitis A in Israel following universal immunization of toddlers. JAMA 2005; 294:202-210.

15. Belmaker I, Dukhan L, Yosef Y, Leventhal A, Dagan R. Elimination of hepatitis a infection outbreaks in day care and school settings in southern Israel after introduction of the national universal toddler hepatitis a immunization program. Pediatr Infect Dis J 2007;26:3640.

16. Yim E, Lee K, Cheon E, Lim M. Factors influencing children's immunization. J Korean Acad Community Health Nurs 2006;17: 283-294. (Korean)

17. Bobo JK, Gale JL, Thapa PB, Wassilak SG. Risk factors for delayed immunization in a random sample of 1163 children from Oregon and Washington. Pediatrics 1993;91:308-314.

18. Orenstein W, Rodewald L, Hinman A, Schuchat A. Immunization in the United States. In: Plotkin SA, Orenstein WA, Offit PA, editors. Vaccines. 5th ed. Philadelphia: Saunders/Elsevier;2008. p.14791510.

19. Fiore A, Baxter LC, Bell BP, Hershow R, Passaro D, Twiddy S, et al. Hepatitis A 2004 vaccination in children: methods and findings of a survey in two states. Am J Prev Med 2007;33:346-352.

20. WHO. Hepatitis A vaccines: WHO position paper. Wkly Epidemiol Rec 2000;75:38-44. 